Af Lars Kjær, lakj@kb.dk, Henrik Tang, heta@kb.dk

og Nejra H. Richter, neta@kb.dk

\title{
Finnerne satser stort på kunstig intelligens
}

Når man kigger på det internationale bibliotekslandskab, står især ét land særligt skarpt for tiden, og det er Finland. Med store satsninger inden for Open Science, virtual reality og kunstig intelligens på tværs af bibliotekssektoren - og ikke mindst publikumssuccesser som Helsinkis storslåede nye hovedbibliotek, Oodi, - har finnerne positioneret sig som en frontløber, og et land vi andre kan lade os inspirere af. I december 2019 sendte Det $\mathrm{Kgl}$. Bibliotek derfor en delegation afsted til det kolde nord for at undersøge, hvad vi kan lære af vores biblioteksglade naboer mod nordøst.

\section{De store universiteter og det lille start-up Iris.ai}

Mens kolleger på Københavns Universitetsbibliotek, Roskilde Universitetsbibliotek, Københavns Universitet og AU Library arbejdede hårdt på at implementere det nye bibliotekssystem, begav tolv medarbejdere fra de samme institutioner sig ud på en rejse med ét klart formål: at indsamle viden og erfaringer til understøttelse af innovation - især inden for kunstig intelligens.

Inden vi rejste, var vi blevet orienteret om, at en række af de nordiske universiteter havde startet et partnerskab med det finske start-up firma Iris.ai. Det lille start-up firma, der efterhånden har vokset sig så stort, at firmaet tæller 20 ansatte, har udviklet et stykke software, der er meget relevant for bibliotekssektoren. Softwaren kan man betragte som en "videnskabelig assistent", hvis assistance er baseret på kunstig intelligens, der har til formål at sikre brugeren en hurtig og effektiv litteratursøgning.
Vi var interesseret i at undersøge, hvad softwaren kunne og lære mere om, hvilke erfaringer universitetet i Helsinki har gjort sig med softwaren i forbindelse med at have introduceret deres studerende og forskere til den.

\section{Kunstig intelligens sparer brugeren for tid}

Vores første stop på turen var på Iris. ai's. Vi holdt mødet i et moderne, urbant og kreativt kontorfællesskab i den indre del af Helsinki. Vi blev mødt af Maria Ritola, der er én af Iris.ai's fire grundlæggere, og af Karita Kasurinen, der er firmaets Head of Customer Success til en snak om det software, som Iris.ai producerer.

Det overordnede formål med softwaren er at finde en effektiv måde til at navigere i den voksende mængde af forskningspublikationer på en let og hurtig måde. Som eksempel forklarede Maria og Karita, at de i samarbejde med Chalmers University i Sverige netop har færdiggjort et studie af softwarens præcision og effektivitet. Målet for studiet var at undersøge, hvor hurtigt og præcist softwaren kunne identificere relevante artikler inden for et emne og reducere i mængden af litteratur. Hvor et menneske skulle bruge 95 dage på at reducere 22.000 artikler til 3.000 artikler af særlig relevans, kunne softwaren klare dette på 21 dage med en præcision på 99,8 \%. Hvis man derimod kunne acceptere en præcision på $85 \%$, kunne tiden blive kortet helt ned til to dage.

Softwaren bidrager til at spare tid, og dette fremhæver Maria Ritola og Karita Kasurinen også. Vi spurgte Karita Kasurinen om, de ikke fandt det problematisk at fokusere på tidsfaktoren, eftersom dette taler ind i en diskurs, der bliver forbundet med forskellige problematikker. For eksempel at der i samfund, hvor tempoet skrues op, bliver mindre tid til refleksion, hvorved risikoen for dårlige beslutninger øges.

Hos Maria og Karita er holdningen dog, at både præcision og effektivitet er væsentlige faktorer, og at softwaren bidrager til at spare brugeren for tid og dermed ressourcer, samt at softwaren ville kunne bidrage til nye tværdisciplinære opdagelser. Den enkelte bruger har stadig kontrollen, insisterer Maria og Karita, da det stadig er op til brugeren selv at forholde sig til resultatet af søgningerne.

\section{Udfordringer i Iris.ai}

Vil studerende eller forskere bruge Iris. ai's software til at komme hurtigere igennem deres litteratursøgning, skal de dog, inden de kaster sig ud i dette, være opmærksomme på, at softwaren 
egner sig bedst til de naturvidenskabelige forskningsområder som for eksempel medicin, kemi og biovidenskab. Dette skyldes for det første, at størstedelen af den litteratur, som softwaren anvender til sine søgninger, stammer fra det naturvidenskabelige område.

En anden væsentlig ting, der er værd at bemærke er, at softwaren søger i Open Access artikler, hvilket medfører at store dele af forskningslitteraturen ikke er inkluderet i søgningerne, eftersom en meget omfattende del af forskningslitteraturen publiceres og indekseres bag betalingsmure på licensbelagte platforme.

Der findes mulighed for at inkludere andre platforme, som for eksempel PubMed, men dette forudsætter en slags "teknisk harmonisering": Grundpakken lader Iris. ai afsøge de bibliografiske poster fra Pubmed, men ønsker man en full-textløsning skal der udvikles en software, der kan håndtere det enkelte biblioteks specifikke licensbelagte samlinger og inkludere disse i sine søgninger.
Udviklingen af dette koster selvsagt penge, men investeres der ikke i dette vil Iris.ai's "semi-automatiserede" søgninger forblive et supplement til "ikke-automatiseret" informationssøgninger i bibliotekskataloger og databaser.

En tredje udfordring er, at Iris.ai's software egner sig bedst til forskningsområder med engelsk som dominerende sprog. Dette hænger dels sammen med, at der publiceres mere på engelsk end på noget andet sprog, dels sam-
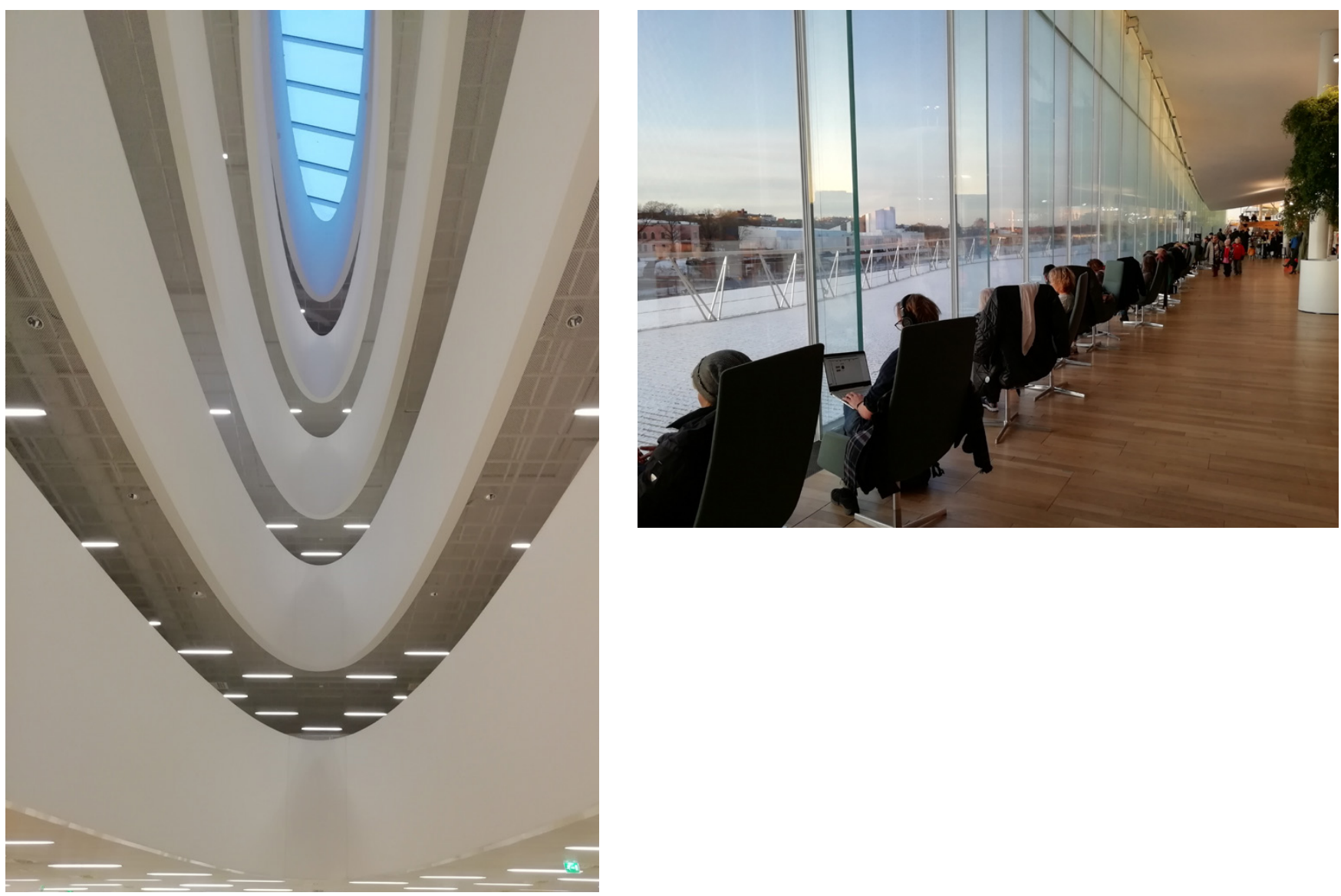


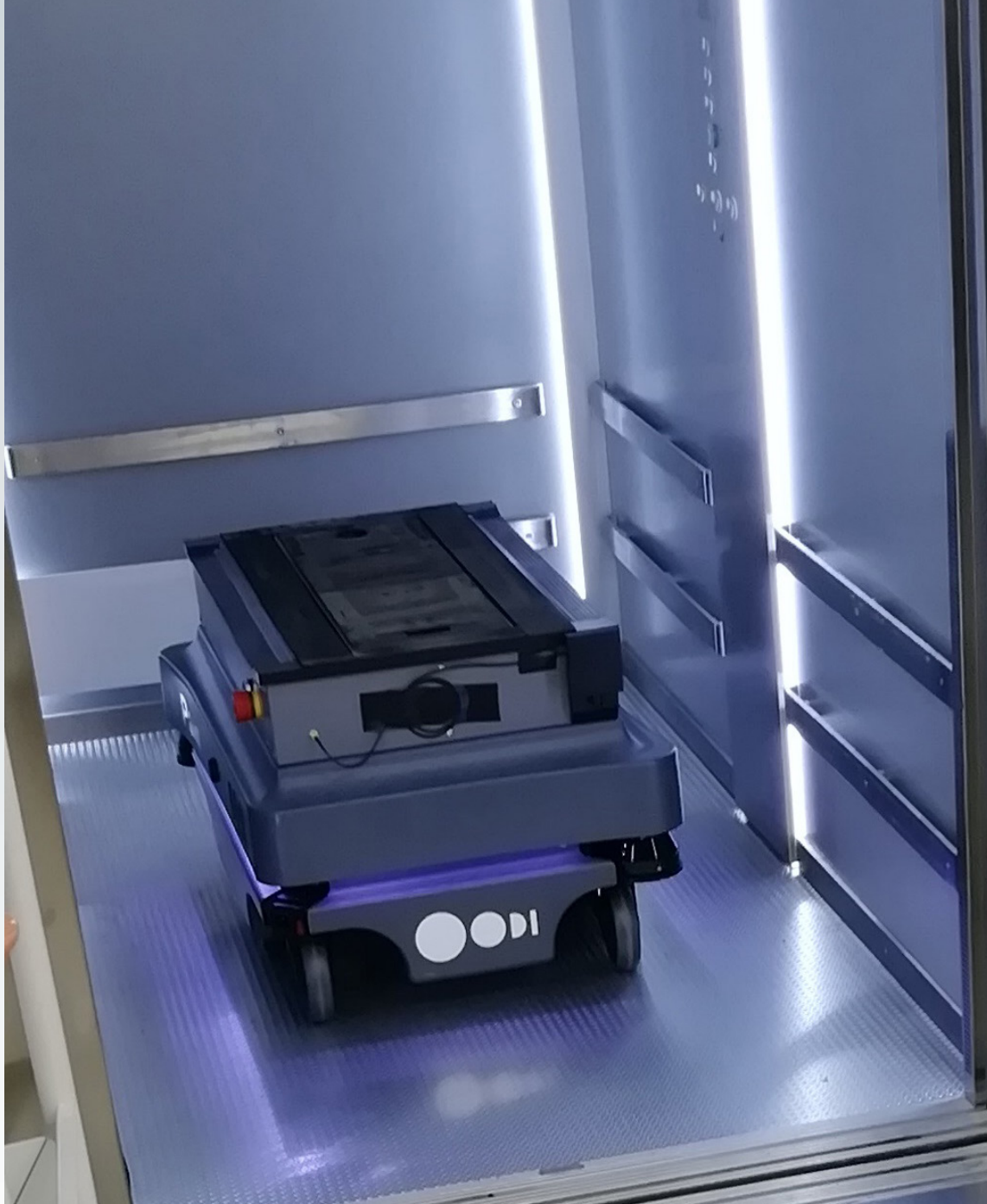

men med den måde, hvorpå softwaren er programmeret.

For de fagområders vedkommende, hvor relevant litteratur næsten udelukkende publiceres på engelsk, vil forskellen mellem resultatet af en "semi-automatiseret" søgning med Iris.ai's software sammenlignet med resultatet af en "ikke-automatiseret" søgning være begrænset.

Det modsatte gør sig gældende inden for de fagområder, hvor relevant litteratur udgives på flere sprog, f.eks. både på fransk, tysk og engelsk. Inden for disse fagområder vil søgeresultaterne lide under betydelige mangler, og tilliden til at Iris.ai's software ville kunne producere relevant læselister vil dermed blive mindre.

\section{Erfaringer med Iris.ai på Helsinki Universitetsbibliotek}

På trods af de udfordringer, der er forbundet med at benytte Iris.si's software, synes finnerne at mene, at der er meget at hente ved at benytte Iris.ai til litteratursøgning.
Formålet med kurserne var at lære brugerne, hvordan softwaren fungerer. Og hvordan fungerer den så?

Iris.ai's softwaren benyttes på en noget anderledes måde end den måde, som vi kender inden for biblioteksverden. En søgning begynder med, at brugeren giver softwaren noget information. Informationen kan enten bestå af cirka 500 ord, som man indtaster i et tekstfelt, for at beskrive sit emne, eller den kan bestå af indholdet af en udvalgt artikel, som man uploader til softwaren.

Softwaren foretager herefter en digital tekstanalyse og identificerer på baggrund af analysen en række nøglebegreber i den informationen, som man har givet. Nøglebegreberne bliver herefter sammenlignet med nøglebegreber i Open Access artikler fra for eksempel CORE, og disse artikler bliver præsenteret i en fin visualisering, der på en let og intuitiv måde sætter brugeren i stand til at inkludere eller ekskludere sammenhængen til det ønskede søgeresultat.

Det, der virkelig adskiller en søgning med Iria.ai fra en traditionel søgning, er den digitale tekstanalyse, der identificerer nøglebegreber. Hvad der helt præcist foregår i den digitale tekstanalyse er relativt svært at gennemskue, eftersom det er forskellige processer, der danner baggrunden for analysen.

Ved at anvende vendinger som "All news are good news" signalerede Jukka Englund, at det overordnede indtryk er, at Iris.ai leverer et glimrende og velkomment innovativt indspark til den mere traditionelle litteratursøgning.

Helsinkis universitetsbibliotek startede samarbejdet med Iris.ai i april 2018 med at organisere en række kurser for medarbejdere og brugere

De brugerrettede kurser blev hovedsageligt annonceret på Helsinkis sundhedsvidenskabelige fakultet, og med 365 tilmeldte deltagere har der eksisteret en relativ stor nysgerrighed blandt studerende og forskere i forhold til at afprøve den nye metode til litteratursøgning, som Iris.ai tilbyder.
Processerne er kendetegnet ved de ud fra en tekst kan beregne en model for, hvad der er en teksts væsentligste indhold. Det vil ikke være forkert at sige, at disse modeller, der bliver beregnet, kan sammenlignes med den katalogisering ved hjælp af bibliografiske metadata, som vi kender fra kategorisering $i$ et bibliotekskatalog. Forskellen består dog i, at modellerne er computerskabte, og de bibliografiske metadata er menneskeskabte.

De computerskabte modeller, der produceres med Iris.ai's software, baserer sig på tekstindhold og gør ikke brug af menneskeskabte katalogisering. At se bort fra al den viden, mennesker har tilføjet, vil nogle nok mene er dumt, mens andre vil bemærke, at det må- 
ske ikke er så dumt endda med nye fortolkninger af information til trods for, at fortolkningen er computerskabt. Modellerne giver i hvert fald en ny mulighed for at kortlægge store mængder af information, og eftersom modellerne kører uden om bibliometriske metadata og citationssystemer, vil software i bedste fald kunne identificere snitflader mellem forskellige fag og på den måde forhåbentlig bidrage til interdisciplinære opdagelser.

Men hvad tænker brugerne så om Iris. ai's software, efter de har deltaget i et kursus? Universitetsbiblioteket har heldigvis efterfølgende været i kontakt med de personer, der har deltaget på kurserne med henblik på at evaluere, hvordan deltagerne vil vurdere Iris. ai's brugbarhed. Evalueringen har vist, at selve den nye metode til litteratursøgning med visualisering af data blev værdsat, men at der også var plads til forbedringer: Således ville kun $48 \%$ anbefale Iris.ai til en ven, hvilket ikke er imponerede, og $80 \%$ af deltagerne fandt det helt afgørende, at Iris. ai ville kunne finde litteratur $i$ andre databaser end Open Access, da størstedelen af den litteratur, som deltagerne benytter, søger de via licensbelagte databaser.

\section{Implementeringen af produktet}

Universiteter, der beslutter sig for at anskaffe sig Iris.ai, starter med et etårig pilotprojekt, hvorefter de tager stilling til, hvorvidt de ønsker at fornye abonnementet. Abonnementet giver premium-adgang til alle universitetets brugere og dermed mulighed for at gøre brug af alle softwarens facetter. Abonnementet inkluderer også kurser for personalet, for eksempel bibliotekspersonale og for brugerne.

Helsinki Universitetsbibliotek har valgt at forlænge sit samarbejde med Iris. ai. Dette skyldes, at universitetet har investeret penge i at få PubMed indlejret i Iris.ai's opsætning, samt at universitetsbiblioteket har en oplevelse af, at Iris.ai på sigt ville kunne bidrage til en bedre service for forskere og studerende.

\section{Medarbejdere på Innovationsstudieturen 2019 var:}

- Erik Engelbrekt Schwägermann, Det Samfundsvidenskabelige Fakultetsbibliotek

- Henrik Tang, Københavns Universitetsbibliotek Nord

- Jannie Løk Jensen, Københavns Universitetsbibliotek Nord

- Jesper Boserup Thestrup, AU Library - Det Kgl. Bibliotek

- Joanna Ball, Roskilde Universitetsbibliotek/Københavns Universitetsbibliotek

- Jonas Kjøller-Rasmussen, Det Teologiske Fakultetsbibliotek, Københavns Universitet

- Lars Kjær, Københavns Universitetsbibliotek, Søndre Campus

- Lorna Wildgaard, Københavns Universitetsbibliotek, Forskerservice

- Michael Svendsen, Københavns Universitetsbibliotek, Forskerservice

- Nejra Hodzic Richter, Københavns Universitetsbibliotek, Søndre Campus

- Solveig Sandal Johnsen, AU Library - Business \& Social Sciences

- Søren Davidsen, Roskilde Universitetsbibliotek

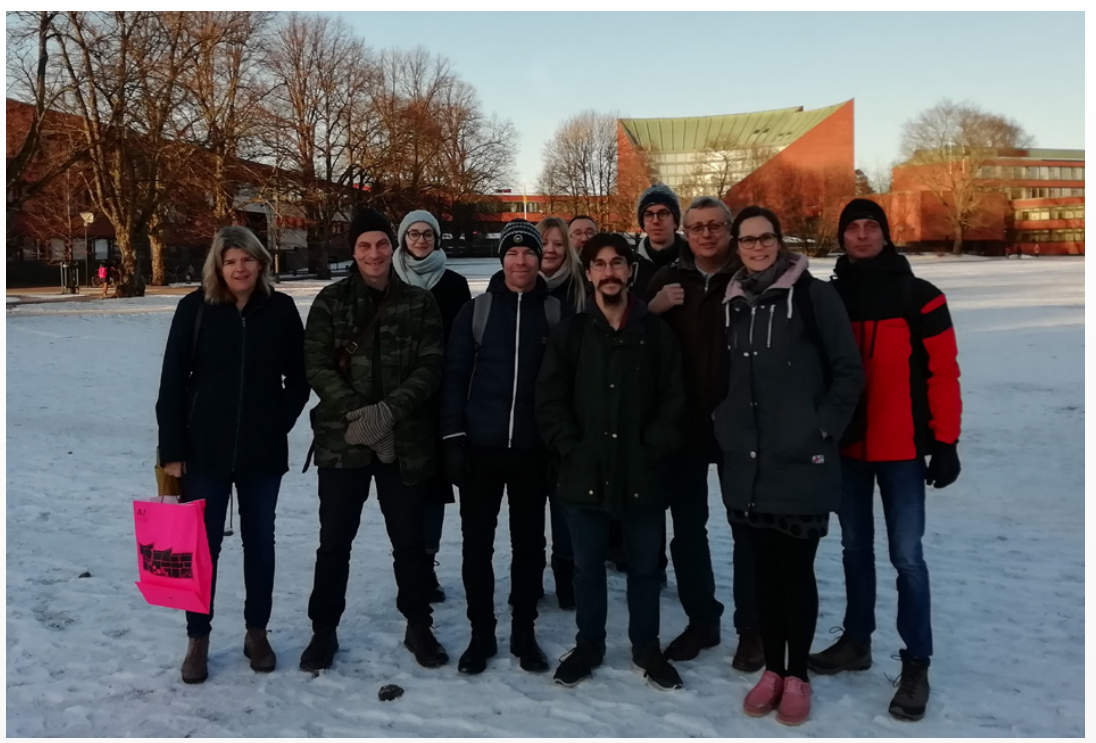

Foruden møder med Iris.ai og Helsinki Universitetsbibliotek var der møder med ansatte på Oodi, Aalto Universitet, CSC - Finnish IT center for science, The e-Infrastructure Reflection Group, Open Science Center på universitet i Jyväskylä og Federation of Finnish Learned Societies. 